\title{
Risk factors for COVID-19 diagnosis, hospitalization, and subsequent all-cause mortality in Sweden: a nationwide study
}

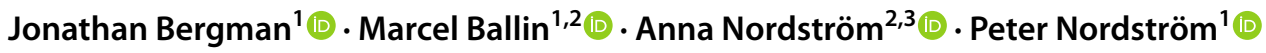

Received: 8 January 2021 / Accepted: 13 February 2021 / Published online: 11 March 2021

(c) The Author(s) 2021

\begin{abstract}
We conducted a nationwide, registry-based study to investigate the importance of 34 potential risk factors for coronavirus disease 2019 (COVID-19) diagnosis, hospitalization (with or without intensive care unit [ICU] admission), and subsequent all-cause mortality. The study population comprised all COVID-19 cases confirmed in Sweden by mid-September 2020 (68,575 non-hospitalized, 2494 ICU hospitalized, and 13,589 non-ICU hospitalized) and 434,081 randomly sampled generalpopulation controls. Older age was the strongest risk factor for hospitalization, although the odds of ICU hospitalization decreased after 60-69 years and, after controlling for other risk factors, the odds of non-ICU hospitalization showed no trend after 40-49 years. Residence in a long-term care facility was associated with non-ICU hospitalization. Male sex and the presence of at least one investigated comorbidity or prescription medication were associated with both ICU and nonICU hospitalization. Three comorbidities associated with both ICU and non-ICU hospitalization were asthma, hypertension, and Down syndrome. History of cancer was not associated with COVID-19 hospitalization, but cancer in the past year was associated with non-ICU hospitalization, after controlling for other risk factors. Cardiovascular disease was weakly associated with non-ICU hospitalization for COVID-19, but not with ICU hospitalization, after adjustment for other risk factors. Excess mortality was observed in both hospitalized and non-hospitalized COVID-19 cases. These results confirm that severe COVID-19 is related to age, sex, and comorbidity in general. The study provides new evidence that hypertension, asthma, Down syndrome, and residence in a long-term care facility are associated with severe COVID-19.
\end{abstract}

Keywords Case-control study $\cdot$ Cohort study $\cdot$ Coronavirus $\cdot$ COVID-19 $\cdot$ Epidemiology $\cdot$ SARS-CoV-2

\section{Introduction}

In December 2019, the Chinese city of Wuhan experienced an outbreak of a severe form of pneumonia of unknown cause. By January 7, the pathogen had been identified as a novel coronavirus, the severe acute respiratory syndrome coronavirus 2 (SARS-CoV-2) [1]. The disease was later designated coronavirus disease 2019 (COVID-19) by the World Health Organization [2]. Although a travel ban in and out of

Peter Nordström

peter.nordstrom@umu.se

1 Unit of Geriatric Medicine, Department of Community Medicine and Rehabilitation, Umeå University, Umeå, Sweden

2 Department of Public Health and Clinical Medicine, Section of Sustainable Health, Umeå University, Umeå, Sweden

3 School of Sport Sciences, UiT the Arctic University of Norway, Troms $\varnothing$, Norway
Wuhan was imposed [3], the virus spread around the globe, and COVID-19 was declared a global pandemic on March 11,2020 [2]. Consequently, there is a large public-health need to study risk factors for developing severe COVID-19. Such studies can help inform strategies for vaccination and disease prevention.

Observational studies have shown that older age, male sex, and comorbidity in general are important risk factors for developing severe COVID-19 [4-8]. However, the results of these studies are inconsistent for particular comorbidities, such as hypertension [5-9], respiratory diseases [4, 6, 7], and cardiovascular disease [5, 7, 8]. Severe COVID-19 has also been associated with demographic factors such as minority ethnicity and low income [7]. The limitations of previous observational studies include small sample size $[5,6,10]$, focus on particular risk factors $[11,12]$, lack of general-population control group [4-6, 8-10], and focus on a few particular outcomes, such as COVID-19-related death $[7,12]$, in-hospital mortality $[4,5,9]$, or intensive care unit 
(ICU)/critical care admission [4, 5]. Therefore, we used data from Swedish national registries to investigate the importance of potential medical and demographic risk factors for COVID-19 diagnosis, hospitalization (with or without ICU admission), and subsequent all-cause mortality during the first wave of COVID-19.

\section{Methods}

\section{Data}

The Public Health Agency of Sweden provided data from its SmiNet database on all cases of COVID-19 confirmed in Sweden until mid-September 2020. Reporting confirmed cases to SmiNet is required by law. We did not have information on the methods of testing used to diagnose the COVID19 cases. Only the first date of diagnosis or positive test for each individual was provided.

We obtained a control population by requesting that Statistics Sweden (the agency of government statistics) randomly sample 5 non-diagnosed individuals for each COVID19 case. Each control was residing in Sweden on January 1, 2020 , and was alive on January 31, 2020. No matching was performed. Statistics Sweden also provided registry data on sex, year and month of birth, country of birth, highest level of completed education in 2018, disposable family income in 2018, home municipality (on December 31, 2019), and a pseudo-anonymized household identifier, indicating which persons lived at the same street address (on December 31, 2019).

The Swedish National Board of Health and Welfare provided registry data on deaths, diagnoses, hospitalizations, prescription medication use, residence in long-term care facility, and use of homemaker service. All deaths in Sweden are recorded in the Cause of Death Register [13]. Diagnoses and hospitalizations are registered in the National Patient Register, to which all health care providers have been required to report hospitalizations since 1987 and physician visits in secondary care (i.e., non-primary care) since 2001 [14]. Each hospitalization or visit is assigned a main diagnosis and one or more secondary diagnoses, which indicate the purpose(s) of the hospitalization or visit. Medical and surgical procedures are also recorded. The National Patient Register has been validated, showing positive predictive values of more than $90 \%$ for most diagnoses, although sensitivity is often lower [14]. For cancer, we also selected diagnoses recorded in the Swedish Cancer Register from 1964 through 2018, so as to obtain a longer lookback period than is possible with the National Patient Register. Health-care providers have been required to report new cancer diagnoses to the Swedish Cancer Register since 1958 [15]. Data on prescription medication use were obtained from the Prescribed Drug
Registry, which records all prescription medications collected at pharmacies in Sweden since July 2005 [16]. Data on residence in a long-term care facility and use of homemaker service were available from the Register for Care and Services for the Elderly and for Persons with Impairments According to the Social Services Act. Local governments are required to report to this register, whose quality is considered adequate for publication by the National Board of Health and Welfare [17]. Homemaker services are domestic services provided to persons (primarily older persons) who live at home but need help with shopping, cleaning, meal preparation, and similar tasks. Local governments are responsible for determining eligibility for these services, although the services may be provided by private businesses.

Information about ICU care was obtained from the Swedish Intensive Care Registry. In 2019, 83 of Sweden's 84 ICUs reported to this registry [18]. The data from the registries were linked using the Personal Identification Number that is issued to each resident of Sweden at the time of birth or immigration. We obtained data files in which Personal Identification Numbers had been replaced by pseudoanonymized identifiers, generated by Statistics Sweden. The study was approved by the Swedish Ethical Review Authority, who waived the requirement of obtaining informed consent (number 2020-02552).

\section{Variables}

We investigated three different outcomes related to COVID19 infection, each reflecting an increased severity of infection: COVID-19 diagnosis without hospitalization; non-ICU hospitalization with confirmed COVID-19 as the main diagnosis (International Classification of Diseases, $10^{\text {th }}$ Revision, Swedish Version, [ICD-10-SE] Code: U071); and ICU hospitalization for confirmed COVID-19 (ICD-10-SE: U071). ICU hospitalizations were traced in SmiNet and non-ICU hospitalizations were traced in the National Patient Register until October 1, 2020. These groups, along with the control group, were followed-up for all-cause mortality until October $1,2020$.

Table 1 shows the demographic variables, comorbidities, and prescription medications that were included in the analysis as potential risk factors for COVID-19. Although pneumonia is sometimes a complication of COVID-19, we included history of pneumonia as a potential risk factor because it may be a marker of frailty or impaired immune system. Variable definitions are available in Supplemental Tables 1 and 2. A composite variable was also constructed, which indicated the presence of at least one of the comorbidities or medications. 
Table 1 Characteristics COVID-19 cases and controls

\begin{tabular}{|c|c|c|c|c|}
\hline Variable & Controls $(n=434,081)$ & Diagnosis $(n=68,575)$ & $\begin{array}{l}\text { Non-ICU hosp. } \\
(\mathrm{n}=13,589)\end{array}$ & ICU hosp. $(n=2494)$ \\
\hline \multicolumn{5}{|l|}{ Demographics } \\
\hline Male sex, n (\%) & $218,736(50.4)$ & $26,808(39.1)$ & $7619(56.1)$ & $1814(72.7)$ \\
\hline \multicolumn{5}{|l|}{ Age, y } \\
\hline Mean (SD) & $41(24)$ & $46(21)$ & 65 (19) & $59(14)$ \\
\hline $0-19, \mathrm{n}(\%)$ & $100,221(23.1)$ & $4,556(6.6)$ & $161(1.2)$ & $25(1.0)$ \\
\hline $20-29$, n $(\%)$ & $54,657(12.6)$ & $13,128(19.1)$ & $381(2.8)$ & $91(3.6)$ \\
\hline $30-39, \mathrm{n}(\%)$ & $57,490(13.2)$ & $11,976(17.5)$ & $821(6.0)$ & $106(4.3)$ \\
\hline $40-49, \mathrm{n}(\%)$ & $54,872(12.6)$ & $12,002(17.5)$ & $1458(10.7)$ & $273(10.9)$ \\
\hline $50-59, \mathrm{n}(\%)$ & $54,808(12.6)$ & $11,896(17.3)$ & $2313(17.0)$ & $640(25.7)$ \\
\hline $60-69, \mathrm{n}(\%)$ & $47,074(10.8)$ & $5623(8.2)$ & $2137(15.7)$ & $753(30.2)$ \\
\hline $70-79$, n $(\%)$ & $42,182(9.7)$ & $2946(4.3)$ & $2550(18.8)$ & $495(19.8)$ \\
\hline $80-89$, n $(\%)$ & $18,653(4.3)$ & $3861(5.6)$ & $2743(20.2)$ & $107(4.3)$ \\
\hline$\geq 90, \mathrm{n}(\%)$ & $4,124(1.0)$ & $2587(3.8)$ & $1025(7.5)$ & $4(0.2)$ \\
\hline Born in Sweden, n (\%) & $349,128(80.4)$ & $51,281(74.8)$ & $8307(61.1)$ & $1376(55.2)$ \\
\hline \multicolumn{5}{|l|}{ Education in 2018, n (\%) } \\
\hline Missing $^{\mathrm{a}}$ & 100,490 & 3,709 & 767 & 125 \\
\hline Primary & $66,656(20.0)$ & $11,837(18.2)$ & $4088(31.9)$ & $625(26.4)$ \\
\hline Secondary & $144,543(43.3)$ & $27,705(42.7)$ & $5306(41.4)$ & $1075(45.4)$ \\
\hline Post-secondary, $<3$ y & $47,858(14.3)$ & $9011(13.9)$ & $1440(11.2)$ & $292(12.3)$ \\
\hline Post-secondary, $\geq 3 \mathrm{y}$ & $74,534(22.3)$ & $16,313(25.1)$ & $1988(15.5)$ & $377(15.9)$ \\
\hline \multicolumn{5}{|l|}{ Family disposable income in $2018, \mathrm{n}(\%)$} \\
\hline Missing $^{\mathrm{a}}$ & 88,321 & 2229 & 237 & 43 \\
\hline Quintile 1 & $68,766(19.9)$ & $12,120(18.3)$ & $4409(33.0)$ & $575(23.5)$ \\
\hline Quintile 2 & $69,086(20.0)$ & $12,407(18.7)$ & $2916(21.8)$ & $522(21.3)$ \\
\hline Quintile 3 & $69,225(20.0)$ & $11,500(17.3)$ & $2429(18.2)$ & $487(19.9)$ \\
\hline Quintile 4 & $69,343(20.1)$ & $14,386(21.7)$ & $1883(14.1)$ & $432(17.6)$ \\
\hline Quintile 5 & $69,340(20.1)$ & $15,933(24.0)$ & $1715(12.8)$ & $435(17.7)$ \\
\hline Long-term care facility, n (\%) & $3928(0.9)$ & $6121(8.9)$ & $1183(8.7)$ & $18(0.7)$ \\
\hline Homemaker service, $\mathrm{n}(\%)$ & $13,144(3.0)$ & $6825(10.0)$ & $4507(33.2)$ & $323(13.0)$ \\
\hline \multicolumn{5}{|l|}{ Stockholm residence ${ }^{\mathrm{b}}$} \\
\hline Missing & 790 & 236 & 69 & 11 \\
\hline $\mathrm{N}(\%)$ & $100,008(23.1)$ & $16,400(24.0)$ & $5636(41.7)$ & $895(36.0)$ \\
\hline \multicolumn{5}{|l|}{ Comorbitities, n (\%) } \\
\hline Any comorbidity/medication & $267,702(61.7)$ & $50,441(73.6)$ & $12,464(91.7)$ & $2218(88.9)$ \\
\hline Cardiovascular disease & $31,922(7.4)$ & $6438(9.4)$ & 4433 (32.6) & $445(17.8)$ \\
\hline Hypertension & $94,582(21.8)$ & $16,416(23.9)$ & $8280(60.9)$ & $1340(53.7)$ \\
\hline Cancer & $33,251(7.7)$ & $5515(8.0)$ & $2861(21.1)$ & $304(12.2)$ \\
\hline Immune disorder & $1125(0.3)$ & $207(0.3)$ & $72(0.5)$ & $16(0.6)$ \\
\hline Autoimmune disease & $19,372(4.5)$ & $3655(5.3)$ & $1551(11.4)$ & $189(7.6)$ \\
\hline Diabetes & $26,026(6.0)$ & $4897(7.1)$ & $3,394(25.0)$ & $651(26.1)$ \\
\hline COPD & $13,133(3.0)$ & $2168(3.2)$ & $1,578(11.6)$ & $169(6.8)$ \\
\hline Asthma & $27,746(6.4)$ & $4493(6.6)$ & $1,208(8.9)$ & $211(8.5)$ \\
\hline Renal failure/chronic kidney disease & $4720(1.1)$ & $1353(2.0)$ & $1,351(9.9)$ & $130(5.2)$ \\
\hline Glomerular disease & $1569(0.4)$ & $337(0.5)$ & $213(1.6)$ & $42(1.7)$ \\
\hline Liver disease & $2628(0.6)$ & $511(0.7)$ & $285(2.1)$ & $66(2.6)$ \\
\hline Dementia/Alzheimer's disease & $3665(0.8)$ & $3618(5.3)$ & $870(6.4)$ & $8(0.3)$ \\
\hline Down syndrome & $297(0.1)$ & $57(0.1)$ & $20(0.1)$ & $8(0.3)$ \\
\hline HIV/AIDS & $357(0.1)$ & $84(0.1)$ & $32(0.2)$ & $9(0.4)$ \\
\hline Sepsis & $3448(0.8)$ & $1018(1.5)$ & $683(5.0)$ & $78(3.1)$ \\
\hline
\end{tabular}


Table 1 (continued)

\begin{tabular}{|c|c|c|c|c|}
\hline Variable & Controls $(n=434,081)$ & Diagnosis $(n=68,575)$ & $\begin{array}{l}\text { Non-ICU hosp. } \\
(\mathrm{n}=13,589)\end{array}$ & ICU hosp. $(n=2494)$ \\
\hline Influenza & $3074(0.7)$ & $922(1.3)$ & $538(4.0)$ & $58(2.3)$ \\
\hline Pneumonia & $17,422(4.0)$ & $3861(5.6)$ & $2193(16.1)$ & $234(9.4)$ \\
\hline Solid organ transplantation & $408(0.1)$ & $85(0.1)$ & $110(0.8)$ & $25(1.0)$ \\
\hline Alcohol intoxication & $11,754(2.7)$ & $2092(3.1)$ & $605(4.5)$ & $119(4.8)$ \\
\hline \multicolumn{5}{|l|}{ Prescription medications, $\mathrm{n}(\%)$} \\
\hline Antithrombotics & $71,744(16.5)$ & $13,797(20.1)$ & $6945(51.1)$ & $941(37.7)$ \\
\hline Lipid-modifying agents & $58,383(13.4)$ & $9,168(13.4)$ & $5652(41.6)$ & $914(36.6)$ \\
\hline Proton-pump inhibitors & $111,107(25.6)$ & $24,016(35.0)$ & $7726(56.9)$ & $1226(49.2)$ \\
\hline Corticosteroids, systemic & $87,788(20.2)$ & $17,651(25.7)$ & $5543(40.8)$ & $879(35.2)$ \\
\hline Immunosuppressants & $8724(2.0)$ & $1,614(2.4)$ & $782(5.8)$ & $137(5.5)$ \\
\hline Antivirals & $32,695(7.5)$ & $7,624(11.1)$ & $1851(13.6)$ & $286(11.5)$ \\
\hline Opioids & $137,169(31.6)$ & $29,214(42.6)$ & $8852(65.1)$ & $1410(56.5)$ \\
\hline
\end{tabular}

$C O P D$ chronic obstructive pulmonary disease, HIV/AIDS human immunodeficiency virus/acquired immunodeficiency syndrome, hosp. hospitalization, $I C U$ intensive care unit, $S D$ standard deviation

a Part of the missing data on education and family income was due to a lack of data on persons aged < 15 years on Dec 31, 2018: 83,198 persons in the control group; 1,616 persons in the diagnosis-only group; 108 persons in the non-ICU hospitalized group; and 15 persons in the ICU hospitalized group

${ }^{\mathrm{b}}$ Residence in Stockholm County (the capital of Sweden) refers to December 31, 2019

\section{Statistical analysis}

Multinomial logistic regression was used to estimate odds ratios for COVID-19 diagnosis or ICU or non-ICU hospitalization. Cox regression was used to estimate hazard ratios for mortality. In each model, persons were excluded if they had missing data on at least one of the included variables.

For non-hospitalized COVID-19 cases, baseline date was defined as the date of testing or diagnosis, whichever came first or was available. If both dates were unavailable, the case was excluded from the analysis. Baseline date for hospitalized cases was the date of ICU or non-ICU admission. For controls, we randomly sampled a date from the baseline dates among cases. Controls who had died by their sampled date were excluded from the analysis.

A subgroup analysis was conducted to examine the prevalence of risk factors for COVID-19 and subsequent mortality in the age group $0-19$ years. We did not estimate odds ratios and hazard ratios in this age group because of the small number of deaths and hospitalized COVID-19 cases.

The incidence of COVID-19 was estimated by dividing the number of cases by the size of the Swedish population (in total and by age group and sex) on December 31, 2019 [19]. The Kaplan-Meier method was used to estimate mortality rates, with confidence intervals based on the $\log$ (survival) transformation. All statistical analyses were performed in $\mathrm{RStudio}$ ( $\mathrm{R}$ version 3.6.2). Statistical significance was determined by $95 \%$ confidence intervals not overlapping 1 .

\section{Results}

There were 87,069 confirmed cases of COVID-19 (incidence rate in Swedish population: 843 cases/100,000 population) and 435,345 general-population controls. Of the cases, 84,633 (97.2\%) had an available date of testing and/or diagnosis, which ranged from January 30, 2020, to September 27, 2020. Most cases were diagnosed between April and June (Supplemental Fig. 1). The incidence was higher in women than in men in most age groups (Supplemental Fig. 2). The incidence was lowest in the age group $0-19$ years and highest in the age group $\geq 90$ years.

By October 1, 2020, 13,589 (15.6\%) of the COVID-19 cases had been non-ICU hospitalized for confirmed COVID19 and 2,494 (2.9\%) had been ICU hospitalized. The 16,083 hospitalized patients lived in 14,936 different households (479 [3.0\%] patients had missing data on household). Of these households, $95.7 \%(n=14,287)$ had only one hospitalized household member (mean 1.04 hospitalized persons per household).

\section{Risk factors for COVID-19 diagnosis and hospitalization}

In the analysis of risk factors for COVID-19 diagnosis and hospitalization, 1264 controls were excluded because they died prior to their assigned baseline date. Furthermore, 2411 non-hospitalized COVID-19 cases were excluded because no date of testing or diagnosis was available. 
Risk factors for COVID-19 diagnosis and hospitalization are presented in Tables 1 and 2. The majority of nonhospitalized COVID-19 cases were women, but the majority of hospitalized cases were men. After adjustment for other risk factors, the odds of non-ICU hospitalization increased until the age group 40-49 years, after which there was no observable trend. Both the adjusted and unadjusted odds of ICU admission increased until the age group 60-69 years and decreased thereafter.

Being born in Sweden was associated with lower odds of COVID-19 diagnosis and hospitalization (Table 2). Higher levels of education were associated with higher odds of COVID-19 diagnosis but with lower odds of hospitalization. After adjustment for other risk factors, family disposable income was positively associated with COVID-19 diagnosis, but there was no clear association with hospitalization.

After adjustment for other risk factors, residence in a long-term care facility was associated with increased odds of diagnosis and, albeit to a lesser degree, non-ICU hospitalization (Table 2). Residence in a long-term care facility was associated with lower odds of ICU admission. Use of homemaker service was associated with both COVID-19 diagnosis and hospitalization (ICU and non-ICU).

Approximately $90 \%$ of ICU and non-ICU hospitalized patients had at least one of the investigated comorbidities or medications, and this was associated with more than twice the odds of ICU and non-ICU hospitalization after adjustment for demographic factors (Tables 1 and 2). The two comorbidities most strongly associated with ICU and non-ICU hospitalization after adjustment for other risk factors were diabetes and Down syndrome. Other comorbidities associated with both ICU and non-ICU hospitalization were hypertension, immune disorder, asthma, influenza, and pneumonia. Comorbidities significantly associated with increased odds of either ICU or non-ICU admission, but not with both, were autoimmune disease, chronic obstructive pulmonary disease (COPD), renal failure/chronic kidney disease, sepsis, solid organ transplantation, and liver disease. Human immunodeficiency virus/acquired immunodeficiency syndrome (HIV/AIDS) and glomerular disease were non-significantly associated with both ICU and non-ICU hospitalization. Alcohol intoxication was associated with lower odds of COVID-19 diagnosis and hospitalization after adjustment for other risk factors.

Cancer was not associated with increased odds of hospitalization after adjustment for other risk factors (Table 2). The unadjusted association was explained by sex, age group, hypertension, cardiovascular disease, corticosteroid use, and opioid use (Supplemental Table 3). Cancer in the past year, however, was associated with COVID-19 diagnosis and non-ICU hospitalization, but not with ICU hospitalization, after adjustment for all variables in Table 2 other than Any Comorbidity/Medication (adjusted odds ratio for diagnosis
1.17, 1.09-1.26; adjusted odds ratio for non-ICU hospitalization 1.30, 95\% CI 1.20-1.42; adjusted odds ratio for ICU admission 0.90, 95\% CI 0.72-1.12).

Cardiovascular disease was associated with slightly increased odds of non-ICU hospitalization, but with lower odds of ICU admission, after adjustment for other risk factors (Table 2). The unadjusted association of cardiovascular disease with ICU admission was explained by age group, sex, hypertension, and diabetes (Supplemental Table 4).

Antithrombotics, proton-pump inhibitors, corticosteroids, and opioids were associated with both ICU and non-ICU hospitalization for COVID-19 after adjustment other risk factors (Table 2). Antivirals and lipid-modifying agents were not associated with either ICU or non-ICU hospitalization after controlling for other risk factors. The unadjusted association for lipid-modifying agents was explained by age, sex, hypertension, diabetes, and cardiovascular disease (Supplemental Table 5). Immunosuppressants were associated with increased odds of ICU hospitalization and slightly increased odds of non-ICU hospitalization, although the associations were not significant.

\section{All-cause mortality in COVID-19}

In the analysis of all-cause mortality, an additional 45 nonhospitalized COVID-19 cases were excluded because they died prior to the date of testing or diagnosis. The median number of days from baseline until the end date of the analysis (October 1, 2020) was 119 days (interquartile range, 98-155 days).

Excess mortality was observed in hospitalized and nonhospitalized COVID-19 cases after adjustment for other risk factors (Fig. 1, Table 3, Table 4). The only demographic factor not associated with all-cause mortality was birth in Sweden (Table 4). Most comorbidities were associated with mortality in excess of any risk conferred by COVID19 (Table 4).

\section{COVID-19 and subsequent mortality in persons aged $0-19$ years}

Male sex was not associated with COVID-19 diagnosis or ICU or non-ICU hospitalization in persons aged 0-19 years (Supplemental Table 6). Hospitalized COVID-19 cases were less often born in Sweden, and they more often had hypertension, cancer, diabetes, COPD, sepsis, pneumonia, and corticosteroid use than did general-population controls and non-hospitalized COVID-19 cases. Asthma and protonpump inhibitors were more common in non-ICU hospitalized and diagnosis-only COVID-19 cases than in generalpopulation controls. There were too few deaths to evaluate excess mortality among COVID-19 cases aged 0-19 years (Supplemental Table 7). 
Table 2 Association between potential risk factors and COVID-19 (reference group: general population controls)

\begin{tabular}{|c|c|c|c|c|c|c|}
\hline \multirow[t]{2}{*}{ Variable } & \multicolumn{3}{|c|}{ Unadjusted Odds Ratio (95\% CI) } & \multicolumn{3}{|c|}{ Adjusted $^{\mathrm{a}}$ Odds Ratio (95\% CI) } \\
\hline & Diagnosis & Non-ICU hosp. & ICU hosp. & Diagnosis & Non-ICU hosp. & ICU hosp. \\
\hline \multicolumn{7}{|l|}{ Demographics } \\
\hline Male sex & $0.63(0.62-0.64)$ & $1.26(1.21-1.30)$ & $2.63(2.41-2.87)$ & $0.64(0.63-0.65)$ & $1.59(1.53-1.65)$ & $3.04(2.76-3.35)$ \\
\hline \multicolumn{7}{|l|}{ Age group, y } \\
\hline $0-19$ & 1 (ref) & 1 (ref) & 1 (ref) & 1 (ref) & 1 (ref) & 1 (ref) \\
\hline $20-29$ & $5.28(5.10-5.47)$ & $4.34(3.61-5.22)$ & $6.67(4.29-10.39)$ & $0.69(0.66-0.73)$ & $2.45(1.69-3.55)$ & $3.62(1.45-9.02)$ \\
\hline $30-39$ & $4.58(4.42-4.75)$ & $8.89(7.51-10.53)$ & $7.39(4.78-11.43)$ & $0.47(0.44-0.50)$ & $4.12(2.86-5.93)$ & $3.70(1.49-9.21)$ \\
\hline $40-49$ & $4.81(4.64-4.99)$ & $\begin{array}{l}16.54(14.05- \\
19.47)\end{array}$ & $\begin{array}{l}19.94(13.24- \\
30.04)\end{array}$ & $0.46(0.43-0.49)$ & $7.25(5.05-10.41)$ & $9.68(3.94-23.77)$ \\
\hline $50-59$ & $4.77(4.61-4.95)$ & $\begin{array}{l}26.27(22.38- \\
30.83)\end{array}$ & $\begin{array}{l}46.81(31.39- \\
69.81)\end{array}$ & $0.45(0.42-0.48)$ & $10.17(7.09-14.60)$ & $20.30(8.30-49.64)$ \\
\hline $60-69$ & $2.63(2.52-2.74)$ & $\begin{array}{l}28.26(24.07- \\
33.18)\end{array}$ & $\begin{array}{l}64.12(43.04- \\
95.53)\end{array}$ & $0.24(0.22-0.25)$ & $8.46(5.89-12.14)$ & $23.97(9.80-58.62)$ \\
\hline $70-79$ & $1.54(1.46-1.61)$ & $\begin{array}{l}37.63(32.08- \\
44.15)\end{array}$ & $\begin{array}{l}47.04(31.47- \\
70.32)\end{array}$ & $0.10(0.09-0.11)$ & $7.31(5.08-10.50)$ & $14.59(5.94-35.81)$ \\
\hline $80-89$ & $4.55(4.35-4.77)$ & $\begin{array}{l}91.54(78.03- \\
107.39)\end{array}$ & $\begin{array}{l}23.00(14.87- \\
35.55)\end{array}$ & $0.12(0.11-0.13)$ & $9.16(6.36-13.19)$ & $5.42(2.17-13.57)$ \\
\hline 90 & $\begin{array}{l}13.80(13.03- \\
14.61)\end{array}$ & $\begin{array}{l}154.72(130.66- \\
183.22)\end{array}$ & $3.88(1.35-11.17)$ & $0.18(0.16-0.19)$ & $10.17(7.02-14.75)$ & $0.84(0.22-3.19)$ \\
\hline Born in Sweden & $0.72(0.71-0.74)$ & $0.38(0.37-0.40)$ & $0.30(0.28-0.32)$ & $0.71(0.69-0.72)$ & $0.38(0.37-0.40)$ & $0.33(0.30-0.37)$ \\
\hline \multicolumn{7}{|l|}{$\begin{array}{l}\text { Education in } \\
2018\end{array}$} \\
\hline Primary & 1 (ref) & 1 (ref) & 1 (ref) & 1 (ref) & 1 (ref) & 1 (ref) \\
\hline Secondary & $1.08(1.05-1.10)$ & $0.60(0.57-0.62)$ & $0.79(0.72-0.88)$ & $1.11(1.08-1.15)$ & $0.87(0.83-0.91)$ & $0.91(0.82-1.01)$ \\
\hline $\begin{array}{l}\text { Post-second- } \\
\text { ary, }<3 \text { y }\end{array}$ & $1.06(1.03-1.09)$ & $0.49(0.46-0.52)$ & $0.65(0.57-0.75)$ & $1.09(1.05-1.13)$ & $0.79(0.74-0.85)$ & $0.80(0.69-0.92)$ \\
\hline $\begin{array}{l}\text { Post-second- } \\
\text { ary, } \geq 3 \text { y }\end{array}$ & $1.23(1.20-1.26)$ & $0.43(0.41-0.46)$ & $0.54(0.47-0.61)$ & $1.19(1.15-1.23)$ & $0.73(0.69-0.78)$ & $0.73(0.63-0.83)$ \\
\hline \multicolumn{7}{|l|}{$\begin{array}{l}\text { Disposable fam- } \\
\text { ily income in } \\
2018\end{array}$} \\
\hline Quintile 1 & 1 (ref) & 1 (ref) & 1 (ref) & 1 (ref) & 1 (ref) & 1 (ref) \\
\hline Quintile 2 & $1.02(0.99-1.05)$ & $0.66(0.63-0.69)$ & $0.90(0.80-1.02)$ & $1.30(1.26-1.35)$ & $0.98(0.92-1.04)$ & $0.93(0.81-1.07)$ \\
\hline Quintile 3 & $0.94(0.92-0.97)$ & $0.55(0.52-0.58)$ & $0.84(0.75-0.95)$ & $1.74(1.69-1.80)$ & $1.07(1.00-1.14)$ & $0.96(0.83-1.10)$ \\
\hline Quintile 4 & $1.18(1.15-1.21)$ & $0.42(0.40-0.45)$ & $0.75(0.66-0.84)$ & $1.88(1.82-1.95)$ & $0.99(0.92-1.07)$ & $0.94(0.81-1.08)$ \\
\hline Quintile 5 & $1.30(1.27-1.34)$ & $0.39(0.36-0.41)$ & $0.75(0.66-0.85)$ & $1.81(1.75-1.88)$ & $0.94(0.87-1.01)$ & $0.84(0.72-0.97)$ \\
\hline $\begin{array}{l}\text { Long-term care } \\
\text { facility }\end{array}$ & $\begin{array}{l}10.73(10.30- \\
11.18)\end{array}$ & $10.44(9.76-11.17)$ & $0.80(0.50-1.27)$ & $9.96(9.33-10.63)$ & $1.17(1.07-1.27)$ & $0.39(0.24-0.63)$ \\
\hline $\begin{array}{l}\text { Homemaker } \\
\text { service }\end{array}$ & $3.54(3.43-3.65)$ & $\begin{array}{l}15.89(15.27- \\
16.54)\end{array}$ & $4.76(4.23-5.36)$ & $2.24(2.12-2.37)$ & $5.30(4.99-5.63)$ & $4.53(3.90-5.25)$ \\
\hline $\begin{array}{l}\text { Stockholm } \\
\text { residence }^{\mathrm{b}}\end{array}$ & 1.05 (1.03-1.07) & $2.38(2.30-2.47)$ & $1.88(1.73-2.04)$ & $0.94(0.92-0.96)$ & $2.28(2.19-2.37)$ & $1.80(1.64-1.96)$ \\
\hline \multicolumn{7}{|l|}{ Comorbitities } \\
\hline $\begin{array}{l}\text { Any comorbidity/ } \\
\text { medication }\end{array}$ & $1.73(1.70-1.76)$ & $6.89(6.48-7.32)$ & $4.99(4.41-5.66)$ & $1.31(1.29-1.34)^{\mathrm{c}}$ & $2.39(2.23-2.57)^{\mathrm{c}}$ & $2.17(1.88-2.50)^{\mathrm{c}}$ \\
\hline $\begin{array}{l}\text { Cardiovascular } \\
\text { disease }\end{array}$ & $1.31(1.27-1.34)$ & $6.10(5.88-6.34)$ & $2.74(2.47-3.03)$ & $1.10(1.05-1.15)$ & $1.08(1.02-1.14)$ & $0.74(0.65-0.85)$ \\
\hline Hypertension & $1.13(1.11-1.15)$ & $5.60(5.40-5.80)$ & $4.17(3.85-4.51)$ & $1.00(0.97-1.03)$ & $1.24(1.18-1.31)$ & $1.42(1.27-1.58)$ \\
\hline Cancer & 1.05 (1.02-1.09) & $3.21(3.08-3.36)$ & $1.67(1.48-1.89)$ & $0.97(0.93-1.00)$ & $1.01(0.96-1.07)$ & $0.81(0.71-0.93)$ \\
\hline Immune disorder & $1.17(1.00-1.35)$ & $2.05(1.61-2.60)$ & $2.48(1.51-4.08)$ & $1.01(0.86-1.19)$ & $1.33(1.01-1.73)$ & $1.79(1.04-3.09)$ \\
\hline $\begin{array}{l}\text { Autoimmune } \\
\text { disease }\end{array}$ & $1.21(1.16-1.25)$ & $2.76(2.61-2.91)$ & $1.76(1.51-2.04)$ & $0.97(0.93-1.02)$ & $1.13(1.05-1.21)$ & $0.95(0.80-1.14)$ \\
\hline Diabetes & $1.21(1.17-1.24)$ & $5.22(5.01-5.44)$ & $5.54(5.07-6.07)$ & $1.13(1.09-1.18)$ & $1.54(1.46-1.62)$ & $1.82(1.62-2.03)$ \\
\hline
\end{tabular}


Table 2 (continued)

\begin{tabular}{|c|c|c|c|c|c|c|}
\hline \multirow[t]{2}{*}{ Variable } & \multicolumn{3}{|c|}{ Unadjusted Odds Ratio (95\% CI) } & \multicolumn{3}{|c|}{ Adjusted $^{\mathrm{a}}$ Odds Ratio (95\% CI) } \\
\hline & Diagnosis & Non-ICU hosp. & ICU hosp. & Diagnosis & Non-ICU hosp. & ICU hosp. \\
\hline COPD & $1.05(1.00-1.10)$ & $4.21(3.98-4.45)$ & $2.33(1.99-2.73)$ & $1.07(1.01-1.13)$ & $1.37(1.28-1.47)$ & $1.12(0.94-1.34)$ \\
\hline Asthma & $1.03(0.99-1.06)$ & $1.43(1.35-1.52)$ & $1.35(1.17-1.56)$ & $1.02(0.98-1.06)$ & $1.22(1.13-1.31)$ & $1.53(1.30-1.79)$ \\
\hline $\begin{array}{l}\text { Renal failure/ } \\
\text { chronic kidney } \\
\text { disease }\end{array}$ & $1.83(1.72-1.95)$ & $10.04(9.43-10.70)$ & $5.00(4.18-5.98)$ & $1.29(1.19-1.39)$ & $1.47(1.36-1.60)$ & $1.18(0.95-1.46)$ \\
\hline $\begin{array}{l}\text { Glomerular } \\
\text { disease }\end{array}$ & $1.35(1.20-1.52)$ & $4.17(3.60-4.83)$ & $4.33(3.14-5.97)$ & $1.03(0.90-1.17)$ & $1.20(1.00-1.43)$ & $1.40(0.97-2.02)$ \\
\hline Liver disease & $1.23(1.12-1.36)$ & $3.52(3.11-3.98)$ & $4.46(3.48-5.72)$ & $0.99(0.90-1.10)$ & $1.07(0.93-1.23)$ & $1.37(1.05-1.79)$ \\
\hline $\begin{array}{l}\text { Dementia/Alzhei- } \\
\text { mer's disease }\end{array}$ & $6.54(6.24-6.85)$ & $8.03(7.45-8.67)$ & $0.38(0.19-0.76)$ & $1.92(1.79-2.05)$ & $1.09(0.99-1.20)$ & $0.15(0.07-0.31)$ \\
\hline Down syndrome & $1.21(0.91-1.61)$ & $2.16(1.37-3.40)$ & $4.52(2.21-9.25)$ & $1.77(1.04-2.99)$ & $3.24(1.55-6.78)$ & $4.26(1.01-17.90)$ \\
\hline HIV/AIDS & $1.50(1.18-1.90)$ & $3.17(2.24-4.49)$ & $4.87(2.58-9.18)$ & $0.99(0.77-1.28)$ & $1.13(0.76-1.68)$ & $1.45(0.73-2.89)$ \\
\hline Sepsis & $1.88(1.75-2.02)$ & $6.61(6.08-7.19)$ & $4.23(3.38-5.28)$ & $1.25(1.15-1.36)$ & $1.20(1.08-1.33)$ & $1.23(0.96-1.59)$ \\
\hline Influenza & $1.92(1.78-2.06)$ & $5.76(5.24-6.32)$ & $3.47(2.68-4.49)$ & $1.23(1.13-1.34)$ & $1.47(1.31-1.64)$ & $1.36(1.02-1.80)$ \\
\hline Pneumonia & $1.43(1.38-1.48)$ & $4.60(4.39-4.83)$ & $2.47(2.16-2.83)$ & $1.12(1.07-1.17)$ & $1.44(1.35-1.53)$ & $1.22(1.05-1.43)$ \\
\hline $\begin{array}{l}\text { Solid organ trans- } \\
\text { plantation }\end{array}$ & $1.32(1.04-1.67)$ & $8.68(7.02-10.72)$ & $10.76(7.17-16.15)$ & $0.92(0.71-1.19)$ & $1.41(1.07-1.84)$ & $1.36(0.82-2.26)$ \\
\hline $\begin{array}{l}\text { Alcohol intoxica- } \\
\text { tion }\end{array}$ & $1.13(1.08-1.19)$ & $1.68(1.54-1.82)$ & $1.80(1.50-2.17)$ & $0.86(0.82-0.90)$ & $0.76(0.69-0.84)$ & $0.80(0.66-0.97)$ \\
\hline \multicolumn{7}{|l|}{$\begin{array}{l}\text { Prescription medi- } \\
\text { cations }\end{array}$} \\
\hline Antithrombotics & $1.27(1.25-1.30)$ & $5.28(5.10-5.47)$ & $3.06(2.82-3.32)$ & $1.01(0.98-1.04)$ & $1.19(1.13-1.25)$ & $1.18(1.06-1.32)$ \\
\hline $\begin{array}{l}\text { Lipid-modifying } \\
\text { agents }\end{array}$ & $0.99(0.97-1.02)$ & $4.59(4.43-4.75)$ & $3.72(3.43-4.04)$ & $0.95(0.91-0.98)$ & $0.98(0.93-1.03)$ & $0.98(0.87-1.09)$ \\
\hline $\begin{array}{l}\text { Proton-pump } \\
\text { inhibitors }\end{array}$ & $1.57(1.54-1.59)$ & $3.83(3.70-3.97)$ & $2.81(2.60-3.04)$ & $1.16(1.14-1.19)$ & $1.32(1.27-1.38)$ & $1.22(1.11-1.33)$ \\
\hline $\begin{array}{l}\text { Corticosteroids, } \\
\text { systemic }\end{array}$ & $1.37(1.34-1.39)$ & $2.72(2.62-2.81)$ & $2.14(1.97-2.33)$ & $1.11(1.09-1.14)$ & $1.26(1.21-1.32)$ & $1.27(1.16-1.40)$ \\
\hline $\begin{array}{l}\text { Immunosuppres- } \\
\text { sants }\end{array}$ & $1.18(1.11-1.24)$ & $2.98(2.76-3.21)$ & $2.83(2.38-3.37)$ & $0.90(0.85-0.97)$ & $1.08(0.98-1.20)$ & $1.22(0.97-1.54)$ \\
\hline Antivirals & $1.54(1.50-1.58)$ & $1.94(1.84-2.04)$ & $1.59(1.40-1.80)$ & $1.17(1.14-1.20)$ & $1.04(0.99-1.11)$ & $1.04(0.91-1.19)$ \\
\hline Opioids & $1.61(1.58-1.63)$ & $4.05(3.90-4.19)$ & $2.82(2.60-3.05)$ & $1.16(1.14-1.18)$ & $1.34(1.28-1.40)$ & $1.16(1.05-1.27)$ \\
\hline
\end{tabular}

COPD chronic obstructive pulmonary disease, HIV/AIDS human immunodeficiency virus/acquired immunodeficiency syndrome, hosp. hospitalization, $I C U$ intensive care unit

${ }^{a}$ Adjusted for all variables in column 1 except for Any Comorbidity/Medication

${ }^{\mathrm{b}}$ Residence in Stockholm County (the capital of Sweden) refers to December 31, 2019

${ }^{\mathrm{c}}$ Adjusted for all demographic variables

\section{Discussion}

This nationwide study confirmed that older age, male sex, and comorbidity in general are risk factors for COVID-19 hospitalization and, with the exception of male sex, risk factors for COVID-19 diagnosis without hospitalization. Older age was the strongest risk factor for COVID-19 hospitalization, but the odds of non-ICU hospitalization showed no trend after 40-49 years after adjustment for other risk factors, and the odds of ICU admission decreased after 60-69 years (with or without adjustment). Furthermore, persons living in long-term care facilities were rarely ICU admitted. Excess all-cause mortality was observed in both hospitalized and non-hospitalized cases, even after controlling for a large number of comorbidities and demographic factors. Children and young people aged 0-19 years were rarely diagnosed with or hospitalized for COVID-19, and there were too few deaths in this age group to evaluate excess mortality.

Almost all (90\%) hospitalized patients had one of the investigated comorbidities or medications, and this was associated with more than twice the odds of ICU and non-ICU hospitalization for COVID-19. As in previous studies [5-7], age was the strongest risk factor for severe COVID-19, and 


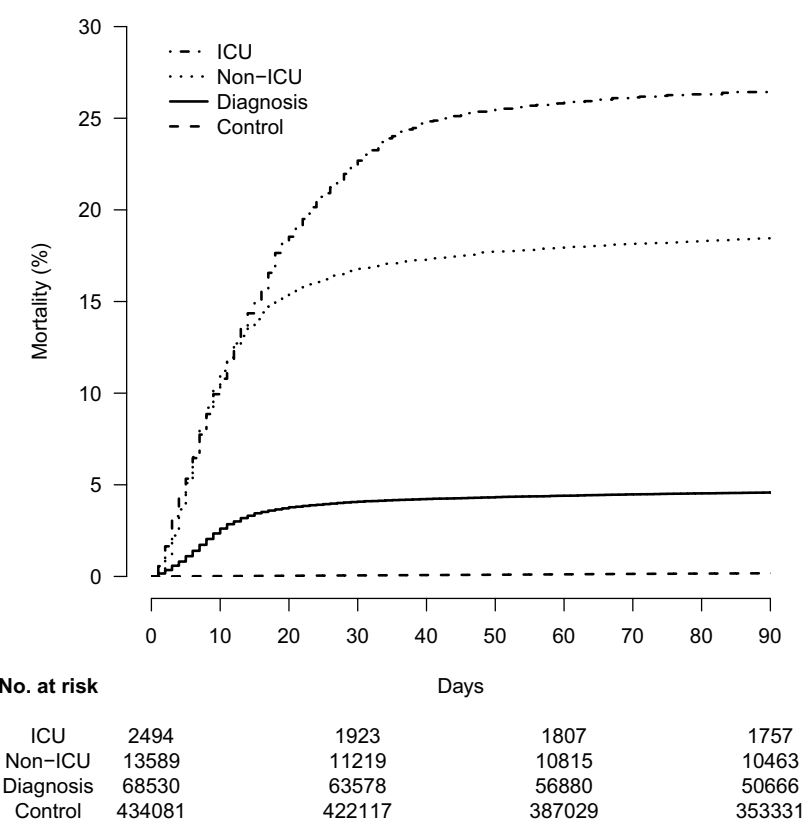

Fig. 1 Risk of all-cause mortality in Swedish COVID-19 cases (intensive care unit [ICU] hospitalized, non-ICU hospitalized, and diagnosed only) confirmed by mid-September 2020 and in generalpopulation controls

none of the comorbidities or medications stood out as a particularly important risk factor for COVID-19 diagnosis or hospitalization. However, Down syndrome, although uncommon, was the condition most strongly associated with COVID-19 hospitalization after adjustment for other risk factors. Down syndrome was also associated with increased all-cause mortality. Previous data on Down syndrome as a risk factor for COVID-19 are limited but consistent with this result [20].
Our study also showed that both diabetes and hypertension were highly prevalent and positively associated with both ICU and non-ICU hospitalization for COVID-19. In previous studies, diabetes has often [5-7, 12], but not always $[8,9]$, been significantly associated with severe COVID19 or COVID-19 mortality after controlling for other risk factors. Previous results for hypertension have been more contradictory [5-9]. We have no explanation for this. We defined hypertension as either a diagnosis of hypertension or a history antihypertensive treatment, so as to increase the sensitivity of detecting hypertension in the study population. Some antihypertensive treatments, namely angiotensin-converting enzyme inhibitors and angiotensin II receptor blockers, have been suspected to increase the risk of contracting COVID-19 and of developing severe COVID-19. However, three previous observational studies found no association with COVID-19 diagnosis [11,21, 22], and only one of these found an association with severe COVID-19 [22]. Two clinical trials also showed that continuation of antihypertensive treatment did not lead to worse outcomes in hospitalized COVID-19 cases [23, 24]. Therefore, it is unlikely that the association with COVID-19 hospitalization in our study is due to an effect of the antihypertensive medications.

After adjustment for other risk factors, we found only a weak association between cardiovascular disease and nonICU hospitalization for COVID-19, and we found no association with ICU hospitalization. This result contradicts the findings of systematic reviews and meta-analyses [25-27]. Previous observational studies have shown conflicting results, perhaps in part due to differences in definition $[5,7$, 8]. Our results suggest that the association between cardiovascular disease and COVID-19 hospitalization is primarily driven by age, sex, hypertension, and diabetes.

We found that cancer in the past year, but not ever history of cancer, was associated with COVID-19 diagnosis and

Table 3 All-cause mortality in COVID-19 cases and general population controls

\begin{tabular}{|c|c|c|c|c|}
\hline Variable & Control $(n=434,081)$ & Diagnosis $(n=68,530)$ & Non-ICU hosp. $(\mathrm{n}=13,589)$ & ICU hosp. $(n=2,494)$ \\
\hline \multicolumn{5}{|l|}{ Number of deaths } \\
\hline 30 days & 248 & 2792 & 2279 & 565 \\
\hline 60 days & 483 & 2999 & 2436 & 643 \\
\hline 90 days & 706 & 3098 & 2501 & 657 \\
\hline Total & 1059 & 3286 & 2612 & 668 \\
\hline Person-months at risk & $1,737,135$ & 245,211 & 54,671 & 9516 \\
\hline $\begin{array}{l}\text { Mortality rate/1,000 } \\
\text { person-months }\end{array}$ & 0.6 & 13.4 & 47.8 & 70.2 \\
\hline \multicolumn{5}{|l|}{ Mortality, \% (95\% CI) } \\
\hline 30 days & $0.1(0.1-0.1)$ & $4.1(3.9-4.2)$ & $16.8(16.2-17.4)$ & $22.7(21.0-24.3)$ \\
\hline 60 days & $0.1(0.1-0.1)$ & $4.4(4.3-4.6)$ & $18.0(17.3-18.6)$ & $25.8(24.1-27.6)$ \\
\hline 90 days & $0.2(0.2-0.2)$ & $4.6(4.4-4.7)$ & $18.5(17.8-19.1)$ & $26.4(24.7-28.1)$ \\
\hline
\end{tabular}

hosp. hospitalization, ICU intensive care unit 
Table 4 Potential risk factors for all-cause mortality

\begin{tabular}{|c|c|c|c|}
\hline \multirow[t]{2}{*}{ Variable } & \multicolumn{3}{|l|}{ Hazard Ratio (95\% CI) } \\
\hline & Unadjusted & $\begin{array}{l}\text { Adjusted for age group, sex, and } \\
\text { COVID-19 }\end{array}$ & Fully adjusted $^{\mathrm{a}}$ \\
\hline \multicolumn{4}{|l|}{ COVID-19 } \\
\hline Control & 1 (ref) & 1 (ref) & 1 (ref) \\
\hline Diagnosis only & $20.54(19.17-22.02)$ & $18.98(17.67-20.37)$ & $10.03(9.27-10.86)$ \\
\hline Non-ICU hospitalization & $84.36(78.54-90.61)$ & $26.38(24.54-28.36)$ & $17.34(16.04-18.75)$ \\
\hline ICU hospitalization & $120.26(109.15-132.49)$ & $92.92(84.17-102.58)$ & $77.41(69.83-85.80)$ \\
\hline \multicolumn{4}{|l|}{ Demographics } \\
\hline Male sex & $1.14(1.09-1.19)$ & $1.56(1.49-1.64)$ & $1.67(1.59-1.76)$ \\
\hline \multicolumn{4}{|l|}{ Age group, y } \\
\hline $0-19$ & 1 (ref) & 1 (ref) & 1 (ref) \\
\hline $20-29$ & $3.09(1.32-7.23)$ & $1.23(0.53-2.88)$ & $0.52(0.17-1.62)$ \\
\hline $30-39$ & $3.92(1.74-8.84)$ & $1.62(0.72-3.66)$ & $0.62(0.21-1.88)$ \\
\hline $40-49$ & $12.98(6.24-27.01)$ & $4.74(2.28-9.86)$ & $2.18(0.79-6.00)$ \\
\hline $50-59$ & $42.29(20.89-85.59)$ & $13.27(6.55-26.88)$ & $5.33(1.98-14.37)$ \\
\hline $60-69$ & $133.04(66.21-267.34)$ & $47.23(23.49-94.96)$ & $13.70(5.10-36.76)$ \\
\hline $70-79$ & 456.41 (227.87-914.17) & $201.51(100.55-403.84)$ & $36.27(13.53-97.23)$ \\
\hline $80-89$ & $1683.57(841.20-3369.51)$ & $541.32(270.30-1084.07)$ & $67.65(25.23-181.44)$ \\
\hline$\geq 90$ & $3819.71(1907.57-7648.56)$ & $846.33(422.31-1696.08)$ & $93.13(34.69-249.97)$ \\
\hline Born in Sweden & $1.02(0.97-1.08)$ & $0.96(0.90-1.01)$ & $1.00(0.94-1.07)$ \\
\hline \multicolumn{4}{|l|}{ Education in 2018} \\
\hline Primary & 1 (ref) & 1 (ref) & 1 (ref) \\
\hline Secondary & $0.42(0.40-0.44)$ & $0.93(0.89-0.98)$ & $0.96(0.92-1.02)$ \\
\hline Post-secondary, $<3$ y & $0.27(0.25-0.29)$ & $0.83(0.76-0.90)$ & $0.89(0.81-0.97)$ \\
\hline Post-secondary, $\geq 3 \mathrm{y}$ & $0.21(0.20-0.23)$ & $0.72(0.67-0.78)$ & $0.83(0.77-0.91)$ \\
\hline \multicolumn{4}{|l|}{ Disposable family income in 2018} \\
\hline Quintile 1 & 1 (ref) & 1 (ref) & 1 (ref) \\
\hline Quintile 2 & $0.43(0.41-0.46)$ & $0.78(0.74-0.83)$ & $0.88(0.83-0.93)$ \\
\hline Quintile 3 & $0.24(0.22-0.26)$ & $0.67(0.62-0.72)$ & $0.79(0.73-0.85)$ \\
\hline Quintile 4 & $0.11(0.10-0.12)$ & $0.57(0.52-0.64)$ & $0.71(0.64-0.79)$ \\
\hline Quintile 5 & $0.09(0.08-0.10)$ & $0.54(0.49-0.61)$ & $0.67(0.59-0.74)$ \\
\hline Long-term care facility & $42.64(40.76-44.61)$ & $2.30(2.17-2.44)$ & $1.74(1.63-1.85)$ \\
\hline Homemaker service & $42.55(40.58-44.62)$ & $1.91(1.80-2.03)$ & $1.41(1.32-1.49)$ \\
\hline Stockholm residence ${ }^{\mathrm{b}}$ & $1.91(1.82-2.00)$ & $1.18(1.12-1.23)$ & $1.09(1.04-1.15)$ \\
\hline \multicolumn{4}{|l|}{ Comorbitities } \\
\hline Any comorbidity/medication & $43.72(35.79-53.42)$ & $2.57(2.09-3.16)$ & $2.34(1.88-2.91)^{\mathrm{c}}$ \\
\hline Cardiovascular disease & $14.85(14.19-15.54)$ & $1.44(1.37-1.51)$ & $1.13(1.07-1.20)$ \\
\hline Hypertension & $19.07(17.91-20.31)$ & $1.58(1.47-1.69)$ & $1.22(1.14-1.32)$ \\
\hline Cancer & $6.47(6.17-6.78)$ & $1.16(1.11-1.22)$ & $1.14(1.08-1.19)$ \\
\hline Immune disorder & $1.78(1.29-2.46)$ & $1.32(0.96-1.82)$ & $1.07(0.77-1.48)$ \\
\hline Autoimmune disease & $3.37(3.16-3.59)$ & $1.24(1.16-1.32)$ & $1.08(1.00-1.16)$ \\
\hline Diabetes & $5.86(5.58-6.16)$ & $1.39(1.32-1.46)$ & $1.23(1.16-1.30)$ \\
\hline COPD & $5.53(5.20-5.89)$ & $1.35(1.27-1.44)$ & $1.08(1.01-1.16)$ \\
\hline Asthma & $1.22(1.12-1.33)$ & $1.04(0.95-1.13)$ & $0.85(0.78-0.93)$ \\
\hline Renal failure/chronic kidney disease & $14.83(13.96-15.74)$ & $1.69(1.59-1.79)$ & $1.30(1.22-1.39)$ \\
\hline Glomerular disease & $3.28(2.70-3.99)$ & $1.48(1.22-1.81)$ & $0.87(0.70-1.07)$ \\
\hline Liver disease & $4.10(3.57-4.72)$ & $1.74(1.51-2.00)$ & $1.27(1.09-1.46)$ \\
\hline Dementia/Alzheimer's disease & $28.29(26.92-29.73)$ & $1.90(1.80-2.01)$ & $1.60(1.50-1.70)$ \\
\hline Down syndrome & $2.70(1.62-4.47)$ & $15.15(9.09-25.24)$ & $10.91(5.41-22.02)$ \\
\hline
\end{tabular}


Table 4 (continued)

\begin{tabular}{llll}
\hline Variable & Hazard Ratio $(95 \%$ CI) & & \\
\cline { 2 - 4 } & Unadjusted & $\begin{array}{c}\text { Adjusted for age group, sex, and } \\
\text { COVID-19 }\end{array}$ & Fully adjusted $^{\mathrm{a}}$ \\
\hline HIV/AIDS & & $1.24(0.56-2.77)$ & $0.80(0.33-1.94)$ \\
Sepsis & $10.10(9.33-10.93)$ & $1.51(1.39-1.63)$ & $1.12(1.03-1.22)$ \\
Influenza & $6.28(5.67-6.95)$ & $1.26(1.14-1.39)$ & $0.93(0.84-1.04)$ \\
Pneumonia & $7.57(7.20-7.97)$ & $1.61(1.53-1.70)$ & $1.30(1.23-1.38)$ \\
Solid organ transplantation & $5.03(3.75-6.74)$ & $3.02(2.25-4.05)$ & $1.66(1.19-2.32)$ \\
Alcohol intoxication & $2.12(1.93-2.34)$ & $1.55(1.40-1.71)$ & $1.12(1.02-1.24)$ \\
Prescription medications & & & $1.16(1.09-1.25)$ \\
Antithrombotics & $15.14(14.36-15.97)$ & $1.50(1.41-1.59)$ & $0.93(0.88-0.98)$ \\
Lipid-modifying agents & $7.58(7.25-7.93)$ & $1.15(1.10-1.21)$ & $1.03(0.98-1.08)$ \\
Proton-pump inhibitors & $4.36(4.16-4.57)$ & $1.25(1.20-1.31)$ & $1.11(1.05-1.17)$ \\
Corticosteroids, systemic & $2.95(2.82-3.08)$ & $1.20(1.15-1.26)$ & $1.00(0.89-1.13)$ \\
Immunosuppressants & $2.51(2.27-2.77)$ & $1.26(1.14-1.39)$ & $0.98(0.92-1.05)$ \\
Antivirals & $2.00(1.88-2.13)$ & $1.04(0.97-1.10)$ & $1.16(1.09-1.22)$ \\
Opioids & $5.80(5.51-6.10)$ & $1.35(1.28-1.42)$ & \\
\hline
\end{tabular}

$C O P D$ chronic obstructive pulmonary disease, HIV/AIDS human immunodeficiency virus/acquired immunodeficiency syndrome, hosp. hospitalization, $I C U$ intensive care unit

${ }^{a}$ Adjusted for all variables in column 1 except for Any Comorbidity/Medication

${ }^{\mathrm{b}}$ On December 31, 2019

${ }^{\mathrm{c}}$ Adjusted for the demographic variables

hospitalization. This finding corroborates the results of three previous observational studies and a meta-analysis $[6-8,27]$. Altogether, only recent cancer appears to be associated with an increased risk of developing severe COVID-19, which could be due to the underlying treatment (e.g., chemotherapy and other medications that affect the immune system).

Our study showed that both COPD and asthma were associated with COVID-19 hospitalization, but only COPD was associated with all-cause mortality after adjustment for COVID-19, age group, and sex. Previous studies have shown conflicting results concerning the association between asthma and COPD and severe COVID-19 or mortality [4, $6,7]$. It is possible that the positive association in our study applies only to severe asthma, as we only had data on diagnoses made in secondary care and hospitalized care.

Concerning demographic factors, the burden of COVID19 was greater in foreign-born persons, as they were more often diagnosed and hospitalized, although all-cause mortality was not higher in foreign-born persons. There was not a clear association between income and COVID-19 hospitalization, although having a disposable family income in the $3^{\text {rd }}$ to $5^{\text {th }}$ quintiles was associated with higher odds of COVID19 diagnosis without hospitalization. Persons with higher levels of education were more often diagnosed and less often hospitalized with COVID-19. This association with COVID19 diagnosis may at least in part be caused by more frequent testing of health care professionals than of the general population. Residence in a long-term care facility was a strong risk factor for COVID-19 diagnosis and subsequent all-cause mortality, although the association with non-ICU hospitalization was weaker and residents of long-term care facilities were rarely ICU admitted. It is well-known that long-term care facilities for older people have been severely affected by COVID-19 [28], but data on such residence has not been available in several large epidemiologic studies [4, 6-8]. Our results confirm that it is important to keep COVID-19 out of long-term care facilities.

A number limitations of this study need to be mentioned. First, the associations presented in this study are not necessarily causal, as there may be residual or unmeasured confounding. Second, the presence of some medical conditions, especially mild conditions, may be underestimated because primary-care diagnoses and complete histories of medical conditions were not available. Third, the likelihood that a person tests positive for COVID-19 is related not only to his or her risk of being infected, but also to his or her access to testing, willingness to be tested, and severity of symptoms. The Swedish strategy for testing was initially to prioritize hospitalized patients, health care professionals, and residents of long-term care facilities [29]. In April 2020, the strategy was extended to include personnel in essential sectors other than health care [30], and in June 2020, the 
strategy was extended to all persons with symptoms [31]. This fact may have biased our results for non-hospitalized COVID-19 cases, especially because most cases were diagnosed between April and June. However, the testing strategy should not have affected our results for hospitalized cases. Fourth, data on smoking and body mass index were not available. The strengths of the study include its nationwide coverage and the availability of many previously suspected risk factors for severe COVID-19. These strengths increase the internal and external validity of the results.

In summary, this nationwide study confirmed that severe COVID-19 is related to age, sex, and general health rather than particular medical conditions. As previously shown, diabetes was a strong risk factor, and only recent cancer was associated with severe COVID-19. Cardiovascular disease was weakly associated with COVID-19 hospitalization after controlling for other risk factors. This study provides new evidence that hypertension, asthma, Down syndrome, and residence in a long-term care facility are associated with severe COVID-19. Excess all-cause mortality was observed in both hospitalized and non-hospitalized COVID-19 cases.

Supplementary Information The online version contains supplementary material available at https://doi.org/10.1007/s10654-021-00732-w.

Authors' contributions Concept and design: PN, JB. Acquisition, analysis, or interpretation of data: All authors. Drafting of the manuscript: JB, MB. Critical revision of the manuscript for important intellectual content: All authors. Statistical analysis: JB. Supervision: PN.

Funding Open access funding provided by Umea University.. Open access funding provided by Umea University. No other funding.

Data availability Individual-level data will not be shared because these are classified as secret under the Swedish Public Access to Information and Secrecy Act.

\section{Declarations}

Conflicts of interest The authors declare that they have no conflicts of interest.

Code availability Statistical code may be obtained from JB upon request.

Ethics approval This study was approved by the Swedish Ethical Review Authority, which waived the requirement of obtaining informed consent (Number 2020-02552).

Open Access This article is licensed under a Creative Commons Attribution 4.0 International License, which permits use, sharing, adaptation, distribution and reproduction in any medium or format, as long as you give appropriate credit to the original author(s) and the source, provide a link to the Creative Commons licence, and indicate if changes were made. The images or other third party material in this article are included in the article's Creative Commons licence, unless indicated otherwise in a credit line to the material. If material is not included in the article's Creative Commons licence and your intended use is not permitted by statutory regulation or exceeds the permitted use, you will need to obtain permission directly from the copyright holder. To view a copy of this licence, visit http://creativecommons.org/licenses/by/4.0/.

\section{References}

1. Phelan AL, Katz R, Gostin LO. The novel coronavirus originating in Wuhan, China: challenges for global health governance. JAMA. 2020;323:709-10.

2. World Health Organization. Listings of WHO's response to COVID-19. https://www.who.int/news/item/29-06-2020-covid timeline. Accessed 21 Dec 2020.

3. Tian H, Liu Y, Li Y, et al. An investigation of transmission control measures during the first 50 days of the COVID-19 epidemic in China. Science. 2020;368:638-42.

4. Docherty AB, Harrison EM, Green CA, et al. Features of 20133 UK patients in hospital with covid-19 using the ISARIC WHO Clinical Characterisation Protocol: prospective observational cohort study. BMJ. 2020;369:m1985.

5. Kim L, Garg S, O'Halloran A, et al. Risk factors for intensive care unit admission and in-hospital mortality among hospitalized adults identified through the US Coronavirus Disease 2019 (COVID-19)-Associated Hospitalization Surveillance Network (COVID-NET). Clin Infect Dis. 2020;2:16.

6. Petrilli CM, Jones SA, Yang J, et al. Factors associated with hospital admission and critical illness among 5279 people with coronavirus disease 2019 in New York City: prospective cohort study. BMJ. 2020;369:m1966.

7. Williamson EJ, Walker AJ, Bhaskaran K, et al. Factors associated with COVID-19-related death using OpenSAFELY. Nature. 2020;584:430-6.

8. Reilev M, Kristensen KB, Pottegård A, et al. Characteristics and predictors of hospitalization and death in the first 11122 cases with a positive RT-PCR test for SARS-CoV-2 in Denmark: a nationwide cohort. Int J Epidemiol. 2020;49:1468-81.

9. Cummings MJ, Baldwin MR, Abrams D, et al. Epidemiology, clinical course, and outcomes of critically ill adults with COVID-19 in New York City: a prospective cohort study. Lancet. 2020;395:1763-70.

10. Guan W, Ni Z, Hu Y, et al. Clinical characteristics of coronavirus disease 2019 in China. N Engl J Med. 2020;382:1708-20.

11. Fosbøl EL, Butt JH, Østergaard L, et al. Association of angiotensin-converting enzyme inhibitor or angiotensin receptor blocker use with COVID-19 diagnosis and mortality. JAMA. 2020;324:168-77.

12. Barron E, Bakhai C, Kar P, et al. Associations of type 1 and type 2 diabetes with COVID-19-related mortality in England: a wholepopulation study. Lancet Diabetes Endocrinol. 2020;8:813-22.

13. Brooke HL, Talbäck M, Hörnblad J, et al. The Swedish cause of death register. Eur J Epidemiol. 2017;32:765-73.

14. Ludvigsson JF, Andersson E, Ekbom A, et al. External review and validation of the Swedish national inpatient register. BMC Public Health. 2011;11:450.

15. Barlow L, Westergren K, Holmberg L, et al. The completeness of the Swedish Cancer Register-a sample survey for year 1998. Acta Oncol (Madr). 2009;48:27-33.

16. Wettermark B, Hammar N, MichaelFored C, et al. The new Swedish Prescribed Drug Register-opportunities for pharmacoepidemiological research and experience from the first six months. Pharmacoepidemiol Drug Saf. 2007;16:726-35.

17. Kroksgård A. Kvalitetsdeklaration-statistik om socialtjänstinsatser till äldre 2019. Stockholm [SE]: Socialstyrelsen; 2020. https:// 
www.socialstyrelsen.se/globalassets/sharepoint-dokument/artik elkatalog/statistik/2020-4-6745-kvalitetsdeklaration.pdf

18. Svenska Intesivvårdsregistret. Svenska Intesivvårdsregistret Årsrapport 2019. 2020. https://www.icuregswe.org/globalassets/ arsrapporter/arsrapport_2019_final.pdf

19. Statistiska centralbyrån. Befolkning efter ålder och kön. År 18602019. https://www.statistikdatabasen.scb.se/pxweb/sv/ssd/START _BE_BE0101_BE0101A/BefolkningR1860/\#. Accessed 27 Nov 2020.

20. Clift A, Coupland C, Keogh R, et al. COVID-19 mortality risk in Down syndrome: results from a cohort study of 8 million adults. Ann Intern Med. 2020;21:20-4986.

21. Mancia G, Rea F, Ludergnani M, et al. Renin-angiotensin-aldosterone system blockers and the risk of COVID-19. N Engl J Med. 2020;382:2431-40.

22. Mehta N, Kalra A, Nowacki AS, et al. Association of use of angiotensin-converting enzyme inhibitors and angiotensin II receptor blockers with testing positive for coronavirus disease 2019 (COVID-19). JAMA Cardiol. 2020;5:1020-6.

23. Cohen JB, Hanff TC, William P, et al. Continuation versus discontinuation of renin-angiotensin system inhibitors in patients admitted to hospital with COVID-19: a prospective, randomised, openlabel trial. Lancet Respir Med. 2021;S2213-2600(20):30558.

24. Lopes RD, Macedo AVS, de Barros E, Silva PGM, et al. Effect of discontinuing vs continuing angiotensin-converting enzyme inhibitors and angiotensin II receptor blockers on days alive and out of the hospital in patients admitted with COVID-19: a randomized clinical trial. JAMA. 2021;325:254-64.

25. Wang Z, Deng H, Ou C, et al. Clinical symptoms, comorbidities and complications in severe and non-severe patients with
COVID-19: a systematic review and meta-analysis without cases duplication. Medicine (Baltimore). 2020;99:e23327.

26. Bae S, Kim SR, Kim M-N, et al. Impact of cardiovascular disease and risk factors on fatal outcomes in patients with COVID-19 according to age: a systematic review and meta-analysis. Heart. 2020;5:1-8.

27. Zheng Z, Peng F, Xu B, et al. Risk factors of critical \& mortal COVID-19 cases: a systematic literature review and meta-analysis. J Infect. 2020;81:e16-25.

28. Burki T. England and Wales see 20000 excess deaths in care homes. Lancet. 2020;395:1602.

29. Folkhälsomyndigheten. Uppdrag för utökad diagnostik av covid19. https://www.folkhalsomyndigheten.se/nyheter-och-press/nyhet sarkiv/2020/mars/uppdrag-for-utokad-diagnostik-av-covid-19/. Accessed 21 Dec 2020

30. Folkhälsomyndigheten. Nationell strategi för att utöka provtagningen för covid-19. https://www.folkhalsomyndigheten.se/nyheteroch-press/nyhetsarkiv/2020/april/nationell-strategi-for-att-utoka -provtagningen-for-covid-19/. Accessed 21 Dec 2020.

31. Regeringen. Regeringen satsar 5,9 miljarder på utökad testning och smittspårning. https://www.regeringen.se/pressmeddelande n/2020/06/regeringen-satsar-59-miljarder-pa-utokad-testning-ochsmittsparning/. Accessed 21 Dec 2020.

Publisher's Note Springer Nature remains neutral with regard to jurisdictional claims in published maps and institutional affiliations. 